INT. J. LANG. COMM. DIS., 2001, VOL. 36, NO. 2, 149-171

\title{
Article
}

\section{Non-specific nature of specific language impairment: a review of the literature with regard to concomitant motor impairments}

\author{
Elisabeth L. Hill \\ Department of Experimental Psychology, University of Cambridge, UK \\ (Received November 1999, accepted April 2000)
}

\begin{abstract}
In the light of emerging suggestions that language and motor deficits may co-occur, the literature on specific language impairment (SLI) was reviewed to investigate the prevalence of co-morbidity between SLI and poor limb motor skill in children diagnosed with language impairments. An extensive literature search was undertaken and the subsequent findings evaluated with particular reference to issues surrounding symptom co-occurrence, as well as to theoretical and aetiological accounts of SLI. Clearly substantial co-morbidity exists between SLI and poor motor skill, suggesting that SLI is not a specific disorder of language, but rather that children with SLI experience a broader range of difficulties, of which motor incoordination is one. Current theoretical explanations of SLI do not account fully for such wide-ranging difficulties and it may be useful in the future to focus on a more detailed explanation in terms of shared cognitive processes or neuromaturational delay to understand further the nature of the disorder, to explain it theoretically and to deal with it practically.
\end{abstract}

Keywords: specific language impairment, movement, classification of disorders.

\section{Introduction}

The predominant focus of description and theory concerning developmental language disorders is that they are specifically linguistic, leading to the use of, among others, the term 'specific language impairment' (SLI). This is diagnosed in children who fail to develop normal language, and in whom this failure is inexplicable in terms of mental or physical handicap, hearing loss, emotional disorder or environmental deprivation. While there has been much debate concerning accurate

Address correspondence to: Institute of Cognitive Neuroscience, 17 Queen Square, London WC1N 3AR, UK; e-mail: eh215@cus.cam.ac.uk 
definition of this disorder (see Bishop 1997 for a review), some subtypes of these language impairments have received attention, including Expressive Language Disorder, Mixed Receptive-Expressive Language Disorder, Phonological Disorder (APA 1994), phonologic-syntactic language deficit and semantic-pragmatic language deficit (Rapin and Allen 1987). Inevitably SLI is seen as exactly that, specific to language. However, over recent years there have been emerging suggestions of the presence of non-linguistic cognitive difficulties (e.g. review by Johnston 1988), including deficits in attention (Tallal et al. 1989) and perceptual deficits (e.g. Tallal et al. 1993) in children with SLI. This paper reviews specific studies that have addressed the existence of motor deficits in children diagnosed with SLI. The term 'SLI' will refer to children with language impairments, but when discussing past work the term chosen by the authors of that work will be used.

A consideration of language and movement skill leads, inevitably, to issues surrounding the classification of neurodevelopmental disorders more generallyare different syndromes overlapping or distinct—and this will be addressed briefly within the framework of the paper. (A full treatment of co-morbidity and aetiological issues across neurodevelopmental disorders requires a separate paper.) The author will argue that documenting and understanding the non-linguistic difficulties of children with SLI will contribute to a better understanding of the child with SLI and how SLI fits into the jigsaw puzzle that is neurodevelopmental disorders. Thus, it will be argued that, broadly speaking, SLI is not 'just' a specific disorder of language, but rather that children with SLI generally experience a broader range of difficulties, of which motor incoordination is one.

\section{Classification of disorders: a brief historical perspective}

Conventional medical classification systems subdivide specific neurodevelopmental disorders into distinct categories, of which language impairments are one subtype. However, language problems have also been described in other neurodevelopmental disorders, e.g. attention deficit hyperactivity disorder (e.g. Tirosh and Cohen 1998). Likewise, children not diagnosed on the basis of motor impairments have been shown to have concomitant difficulties on certain tasks involving motor control (e.g. developmental dyslexia; Nicolson and Fawcett 1994).

There are two possible accounts of this systematic overlap. The first maintains that the sharp distinction between neurodevelopmental disorders made in textbooks and classification schemes may be artificial. Rather than there being discrete groups of children, some with language problems, some with reading problems, others with motor coordination or attentional problems, it may be that all these impairments tend to co-occur in developmentally disordered children, and that those with highly specific deficits are the exception rather than the rule. An alternative view is that there are clear-cut distinctions between neurodevelopmental disorders, and that the similarities in motor impairments are only superficial.

The first of these views is reminiscent of the discussions of a concept previously described as 'minimal brain damage' (MBD). Certainly, poor motor performance has been regarded as an essential component when diagnosing the syndrome of MBD (Dunn et al. 1986). However, this term was favoured up until the 1960s to describe a heterogeneous group of behavioural syndromes, learning disorders, language difficulties and motor disabilities. Owing to the diverse symptoms of children termed MBD, as well as the negative overtones of the label, and the lack of an 
operational definition of the term, the focus of research began to change. Emphasis began to be placed on defining children's difficulties in terms of specific, recognizable and homogeneous groups, diagnosed on the basis of key symptoms and, therefore, making explicit the symptom(s) that were clearly impaired (in the case of language disorders, for example, the presence of a language problem). This led to the fractionation of disorders (the second view described above), and a potentially misrepresentative idea that many neurodevelopmental disorders are distinct, rather than overlapping entities. Hence, there was a movement away from the use of an umbrella term (MBD), to the use of very specific, non-overlapping terms to describe neurodevelopmental disorders.

More recent documentation has indicated that, perhaps, a middle-ground must be found between the MBD and distinct syndrome views described above, as increasing overlap is being identified between what would have been considered, even up until a few years ago, to be diverse, independent disorders (e.g. Kaplan et al. 1998).

\section{Motor skill in SLI}

There are several reasons for which SLI has, in the past, been considered to be a specific disorder, including the way in which disorders are classified, and the fundamental basis of language in society. Given the latter it is not difficult to see that a child's language impairment may be recognized more quickly, by more people and may be considered more central than, say, the same child's movement skills.

To evaluate the range and severity of any motor deficits associated with SLI, a comprehensive literature search was conducted to compile a list of published studies in which children with language impairments had been examined explicitly on motor measures, and specifically on limb coordination. Two databases were used to generate a list of studies that have investigated non-linguistic ability in children with SLI. The PsychLit database allows searches to be made for papers published since 1974, while the Institute for Scientific Information's (ISI) Web of Science (formerly known as BIDS-ISI) allows searches for papers published since 1981 and provides access to the ISI Citation Indexes operated by MIMAS at the University of Manchester, UK. Searches were made on both the Science and Social Science Citation Indexes of this database. To provide the opportunity to locate as many studies as possible, broad search terms were used. The key term 'language' was used in conjunction with terms that implied dysfunction, specifically 'disorder', 'difficulty', 'problems' and 'impairment', and these were identified by the search engine from either the title, keywords and/or abstract (i.e. any one of the search terms could occur in either the title and/or abstract and/or the keywords of the paper). Such broad search terms were used to ensure, insofar as possible, that whatever label used in a study to name the language impairment, these studies would be identified by the search engine. The use of 'language' in all search attempts clearly allows for a very inclusive approach (note that the search was not narrowed by including the search term 'children'). In all, 5000 papers were identified on these databases using these search terms (e.g. language and disorder; language and difficulty), of which the majority were not relevant to the purpose of this task, being unrelated to language disorders associated with development.

Once identified, there were a number of criteria for a study to be included in the list; (1) papers must be written in English, (2) the experimental group must be 
a group diagnosed with only a specific neurodevelopmental disorder of language, (3) explicit comparison of the experimental group must be to a well-matched normally developing control group or standardized test norms on tasks of limb movements, and (4) children with learning disabilities, a pervasive developmental disorder, or a known medical condition were not eligible to be included. Review papers were not included, although these were used to identify further relevant experimental studies. The studies identified others that were not found on the PsychLit and Web of Science databases, thus increasing the scope of this review paper. A list of the studies addressing limb coordination skill was compiled from among the studies of SLI. Table 1 shows the relevant results of this search. Clearly, while comprehensive, this is a non-exbaustive list of studies where limb coordination has been assessed in children with SLI. Papers not contained in these databases will obviously not be accessed, although it is hoped that by using these papers as a way of accessing others, few significant studies will have been omitted.

Twenty-eight papers assessing limb coordination in children with language impairments were found using the search techniques outlined above (table 1). Thus, the rationale for further consideration of (1) the nature of such limb coordination difficulties and (2) the reasons for such overlap was supported and these studies will now be considered in more detail.

\section{Nature of the motor deficits}

Given the clear concomitance of language and coordination impairments highlighted above, it is of interest to consider further the nature of the movement abilities of children with SLI. As a first step it is useful to establish how the movement skill of children with SLI compares with that seen in children diagnosed with developmental coordination disorder (DCD). DCD is diagnosed in a similar manner to SLI, but on the basis of coordination. It is a neurodevelopmental disorder defined in terms of the child experiencing movement difficulties out of proportion with general development and in the absence of any medical condition (e.g. cerebral palsy) or identifiable neurological disease. Movement difficulties interfere significantly with activities of daily living such as dressing, eating and walking as well as with academic achievement (APA 1994). In the past, DCD has been referred to by a series of names including 'clumsy child syndrome' (Gubbay 1975) and 'specific developmental disorder of motor function' (WHO 1992). Although SLI and DCD can co-occur (APA 1994), most children with DCD are supposed to have normal language functioning and, indeed, the typical pattern is to find that Verbal IQ is higher than Performance IQ in this disorder.

The first comparison of motor skill in these two neurodevelopmental disorders comes from the use of the 'Movement Assessment Battery for Children', or Movement ABC (Henderson and Sugden 1992), a revision of the 'Test of Motor Impairment' (TOMI; Stott et al. 1984). This test is in widespread use in the UK both as an assessment tool and in research and includes both a checklist and a performance section. The latter tests manual dexterity, ball skills and static and dynamic balance across a total of eight tasks.

Children who fall below the 15th percentile on the Movement ABC are generally considered to show a DCD. Five of the studies reported in table 1 included the Movement ABC, or its predecessor the TOMI, as one of the motor tests used with a sample of children with SLI. A significant number of the children in each of 
Table 1. Studies that have assessed explicitly the limb coordination difficulties of children with specific language impairments in comparison with a normally developing control group or standardised test data

\begin{tabular}{lll}
\hline Reference & Age \\
Language diagnosis & Limb coordination tests \\
\hline
\end{tabular}

Jenkins and Lohr (1964) articulation disorder

Johnston et al. (1981) language impairment

Stark and Tallal (1981) language impairment

Aram and Horwitz developmental verbal $(1983)^{\ddagger}$

dyspraxia

Hughes and Sussman (1983)

Crary and Towne $(1984)^{\ddagger}$

Cermak et al. (1986)

Wiznitzer et al. (1986) $)^{\dagger \neq}$ developmental language

Bishop and

Edmundson (1987)

Archer and Witelson developmental dysphasia $(1988)^{\dagger}$

Dewey et al. (1988)

Sommers $(1988)^{\ddagger}$ disorder:

verbal dyspraxia

phonologic-syntactic

lexical-syntactic

semantic-pragmatic

articulation impairment:

SMR-impaired ${ }^{*}$

SMR-unimpaired

specific language

impairment:

SLI good outcome

SLI poor outcome general delay

8-13 unspecified tasks including finger opposition, Purdue pegboard (Tiffin 1968), hopping, running, throwing, catching

4-5.5 pegmoving (Annett 1972)

(SLI-

longitudinal;

Controls crosssectional)

4-9 unspecified tests of repetitive finger tapping, pegmoving, posture imitation

4-7 repetitive finger tapping, production of single and sequences of limb gestures, non-symbolic motor sequencing test

5-9 Fine-Motor Skills Checklist impaired 
Table 1. (Continued)

\begin{tabular}{|c|c|c|c|}
\hline Reference & Language diagnosis & $\begin{array}{l}\text { Age } \\
\text { (years) }\end{array}$ & Limb coordination tests \\
\hline $\begin{array}{l}\text { Crary and Anderson } \\
(1990)^{\dagger}\end{array}$ & $\begin{array}{l}\text { developmental verbal } \\
\text { dyspraxia }\end{array}$ & not given & $\begin{array}{l}\text { unspecified hand posture } \\
\text { sequencing task }\end{array}$ \\
\hline Robinson $(1991)^{\ddagger}$ & $\begin{array}{l}\text { speech and language } \\
\text { disorder }\end{array}$ & $9-17$ & Test of Motor Impairment \\
\hline Katz et al. (1992) & language impairment & $\begin{array}{c}4,6,8 \\
\text { (longitudinal) }\end{array}$ & $\begin{array}{l}\text { rapid automatized naming (manual), } \\
\text { finger opposition, coins in box }\end{array}$ \\
\hline $\begin{array}{l}\text { Powell and Bishop } \\
\text { (1992) }\end{array}$ & $\begin{array}{l}\text { specific language } \\
\text { impairment }\end{array}$ & $6-12$ & $\begin{array}{l}\text { breadthreading, pegmoving, ball- } \\
\text { rolling with stick, ball-rolling with } \\
\text { foot, balance, throw-clap-catch }\end{array}$ \\
\hline $\begin{array}{l}\text { Bradford and Dodd } \\
\text { (1994) }\end{array}$ & $\begin{array}{l}\text { developmental speech } \\
\text { disorder: } \\
\text { phonologically delayed } \\
\text { phonologically } \\
\text { consistent errors } \\
\text { phonologically } \\
\text { inconsistent errors }\end{array}$ & $3-6$ & $\begin{array}{l}\text { pegmoving, Motor Accuracy Test- } \\
\text { Revised (Ayres 1980) }\end{array}$ \\
\hline $\begin{array}{l}\text { Bradford and Dodd } \\
\text { (1996) }\end{array}$ & $\begin{array}{l}\text { speech disorders: } \\
\text { developmental verbal } \\
\text { dyspraxia } \\
\text { phonologically delayed } \\
\text { phonologically } \\
\text { consistent errors } \\
\text { phonologically } \\
\text { inconsistent errors }\end{array}$ & $3-6$ & $\begin{array}{l}\text { upper limb speed and dexterity } \\
\text { subtest of the Bruininks- } \\
\text { Osteretsky Test of Motor } \\
\text { Proficiency (Bruininks 1978) }\end{array}$ \\
\hline Fein et al. $(1996)^{\ddagger}$ & $\begin{array}{l}\text { developmental language } \\
\text { disorder }\end{array}$ & 4 & $\begin{array}{l}\text { Annett pegboard (Kilshaw and } \\
\text { Annett 1983), Vineland Motor } \\
\text { Domain (Sparrow et al. 1984), } \\
\text { Seguin Formboard (Stutsman 1931), } \\
\text { pantomime object use (Manual } \\
\text { Expression subtest of ITPA) }\end{array}$ \\
\hline Gross-Tsur et al. (1996) $)^{\dagger}$ & $\begin{array}{l}\text { developmental language } \\
\text { disorder }\end{array}$ & preschool & $\begin{array}{l}\text { unspecified neurological } \\
\text { examination (including gross and } \\
\text { fine motor skill) }\end{array}$ \\
\hline $\begin{array}{l}\text { Schwartz and Regan } \\
(1996)^{\ddagger}\end{array}$ & receptive language delay & $4-7$ & $\begin{array}{l}\text { Response Speed and Upper Limb } \\
\text { Speed and Dexterity subtests of } \\
\text { theBruininks-Osteretsky Test of } \\
\text { Motor Proficiency }\end{array}$ \\
\hline Dewey and Wall (1997) & language impairment & $6-10$ & $\begin{array}{l}\text { production and imitation of } \\
\text { symbolic limb gestures }\end{array}$ \\
\hline $\begin{array}{l}\text { Owen and McKinlay } \\
\text { (1997) }\end{array}$ & $\begin{array}{l}\text { speech and language } \\
\text { disorder }\end{array}$ & $4-7$ & $\begin{array}{l}\text { Wallin pegboard (Merrill Palmer } \\
\text { 1975), breadthreading (Griffiths } \\
\text { 1970), buttoning (Merrill Palmer } \\
\text { 1975), placing crosses in box }\end{array}$ \\
\hline Preis et al. (1997) & $\begin{array}{l}\text { phonologic-syntactic } \\
\text { disorder }\end{array}$ & $4-12$ & tapping, aiming, pegmoving \\
\hline
\end{tabular}


Table 1. (Continued)

\begin{tabular}{|c|c|c|c|}
\hline Reference & Language diagnosis & $\begin{array}{l}\text { Age } \\
\text { (years) }\end{array}$ & Limb coordination tests \\
\hline Hill (1998) & $\begin{array}{l}\text { specific language } \\
\text { impairment: } \\
\text { Clumsy-SLI } \\
\text { non-Clumsy-SLI }\end{array}$ & $7-12$ & $\begin{array}{l}\text { Movement ABC (Henderson and } \\
\text { Sugden 1992), production and } \\
\text { imitation of symbolic limb gestures, } \\
\text { imitation of simple and complex } \\
\text { non-symbolic hand/arm } \\
\text { movements }\end{array}$ \\
\hline Hill et al. (1998) & $\begin{array}{l}\text { specific language } \\
\text { impairment: } \\
\text { Clumsy-SLI } \\
\text { non-Clumsy-SLI }\end{array}$ & $7-12$ & $\begin{array}{l}\text { Movement } \mathrm{ABC} \text {, error analysis of } \\
\text { production and imitation of } \\
\text { symbolic limb gestures }\end{array}$ \\
\hline Rintala et al. (1998) & $\begin{array}{l}\text { developmental language } \\
\text { disorder: } \\
\text { expressive } \\
\text { mixed receptive- } \\
\text { expressive }\end{array}$ & $6-10$ & Movement $\mathrm{ABC}$ \\
\hline $\begin{array}{l}\text { Smith and Bryson } \\
\text { (1998) }\end{array}$ & receptive language delay & $6-17$ & $\begin{array}{l}\text { imitation of non-symbolic manual } \\
\text { postures (unimanual, bimanual) and } \\
\text { posture sequences }\end{array}$ \\
\hline
\end{tabular}

${ }^{\dagger}$ Meeting abstract.

¥ No normally developing control group (standardised test norms used).

${ }^{*}$ Sequenced Motor Rate test.

these studies fell at or below the 15th percentile on the Movement ABC: with 40, 60, 71 and 90\% for Cermak et al. (1986), Hill (1998), Hill et al. (1998), Rintala et al. (1997) and Robinson (1991) respectively. This is in contrast to the estimated prevalence of DCD being 6\% (APA 1994). Thus, it appears that children with SLI do have very significant movement difficulties.

Moving on to a consideration of the performance of children with SLI on experimental tests of motor function, many tasks have been used to assess the performance of children with SLI, and these can be divided into fine/gross motor tasks and tasks assessing praxis. Arguably these involve overlapping but different skills and, therefore, will be considered separately.

\section{Fine/gross motor ability}

Tasks assessing fine and gross motor function include timed peg moving, finger opposition and bead threading as well as line walking, hopping and tasks of balance.

The majority of studies reported in this section have focused on fine motor tasks, and particularly on time taken to complete the task as the variable of interest. Typically children with SLI are reported to be impaired relative to their normally developing peers (Johnston et al. 1981, Hughes and Sussman 1983, Bishop and Edmundson 1987, Katz et al. 1992, Powell and Bishop 1992, Bradford and Dodd 1994, Owen and McKinlay 1997, Preis et al. 1997), although on some repetitive finger tapping tasks performance is unimpaired (Archer and Witelson 1988, Dewey et al. 1988), as is the task of placing crosses in boxes (Owen and McKinlay 1997). In contrast, where performance accuracy on a fine motor task has been assessed, 
Table 2. Studies shown in table 1 that have assessed fine and/or gross motor skill. Tasks used and the magnitude of any group differences are shown

\begin{tabular}{|c|c|c|c|c|c|}
\hline \multirow[b]{2}{*}{ Reference } & \multicolumn{2}{|c|}{ Fine motor } & \multicolumn{2}{|c|}{ Gross motor } & \multirow{2}{*}{$\begin{array}{c}\% \text { SLI } \\
\text { children } \\
\text { impaired } \\
\text { MABC/ } \\
\text { TOMI }\end{array}$} \\
\hline & Impaired & Unimpaired & Impaired & Unimpaired & \\
\hline $\begin{array}{l}\text { Jenkins and Lohr } \\
\text { (1964) }\end{array}$ & $\begin{array}{l}\text { dynamic manual } \\
\text { coordination } \\
\text { simultaneous } \\
\text { voluntary } \\
\text { movements } \\
\text { synkinesia }\end{array}$ & 1 & $\begin{array}{l}\text { general static } \\
\text { coordination } \\
\text { general dynamic } \\
\text { coordination }\end{array}$ & - & - \\
\hline $\begin{array}{l}\text { Johnston et al. } \\
\text { (1981), Stark and } \\
\text { Tallal (1981) }\end{array}$ & $\begin{array}{l}\text { coins }^{*} \\
\text { finger } \\
\text { opposition } \\
\text { (number) }^{* *}\end{array}$ & $\begin{array}{l}\text { finger opposition } \\
\text { (errors) }\end{array}$ & hops $^{* *}$ & $\begin{array}{l}\text { line walking } \\
\text { unipedal stand } \\
\text { bipedal stand }\end{array}$ & - \\
\hline $\begin{array}{l}\text { Hughes and } \\
\text { Sussman (1983) }\end{array}$ & $\begin{array}{l}\text { repetitive } \\
\text { tapping }\end{array}$ & - & - & - & - \\
\hline $\begin{array}{l}\text { Cermak et al. } \\
(1986)\end{array}$ & - & - & - & - & $40^{*}$ \\
\hline $\begin{array}{l}\text { Bishop and } \\
\text { Edmundson } \\
\text { (1987) }\end{array}$ & pegmoving & - & - & - & - \\
\hline $\begin{array}{l}\text { Archer and } \\
\text { Witelson (1988) }\end{array}$ & - & $\begin{array}{l}\text { repetitive } \\
\text { tapping } \\
\text { pegmoving }\end{array}$ & - & - & - \\
\hline $\begin{array}{l}\text { Dewey et al. } \\
\text { (1988) }\end{array}$ & - & $\begin{array}{l}\text { repetitive } \\
\text { tapping }\end{array}$ & - & - & - \\
\hline Robinson (1991) & - & - & - & - & 90 \\
\hline Katz et al. (1992) & $\begin{array}{l}\text { finger } \\
\text { opposition } \\
(\text { ages } 4 \text { and } 8)^{* *}\end{array}$ & $\begin{array}{l}\text { finger opposition } \\
\text { (age 6) } \\
\text { coins }\end{array}$ & - & - & - \\
\hline $\begin{array}{l}\text { Powell and Bishop } \\
\text { (1992) }\end{array}$ & $\begin{array}{l}\text { pegs }{ }^{* *} \\
\text { beads }\end{array}$ & - & $\begin{array}{l}\text { balance (pref) } \\
\text { balance (np) } \\
\text { throw-clap-catch }^{*} \\
\text { ball rolling-stick } \\
\text { (faults pref } \\
\text { hand) }{ }^{* *}\end{array}$ & $\begin{array}{l}\text { ball rolling-stick } \\
\text { (faults np hand) } \\
\text { ball rolling-stick } \\
\text { (time) } \\
\text { ball rolling-foot }\end{array}$ & - \\
\hline $\begin{array}{l}\text { Bradford and } \\
\text { Dodd (1994) }\end{array}$ & $\begin{array}{l}\text { motor } \\
\text { accuracy }^{* *}\end{array}$ & pegs & - & - & - \\
\hline $\begin{array}{l}\text { Bradford and } \\
\text { Dodd (1996) }\end{array}$ & $\begin{array}{l}\text { speed and } \\
\text { dexterity }^{* *}\end{array}$ & - & - & - & - \\
\hline $\begin{array}{l}\text { Gross-Tsur et al. } \\
\text { (1996) }\end{array}$ & $\begin{array}{l}\text { yes } \\
\text { (unspecified) }\end{array}$ & unknown & $\begin{array}{l}\text { yes } \\
\text { (unspecified) }\end{array}$ & unknown & - \\
\hline $\begin{array}{l}\text { Owen and } \\
\text { McKinlay (1997) }\end{array}$ & $\begin{array}{l}\text { pegs }^{* *} \\
\text { beads }^{* *} \\
\text { buttons }\end{array}$ & crosses & - & - & - \\
\hline
\end{tabular}


Table 2. (Continued)

\begin{tabular}{|c|c|c|c|c|c|}
\hline \multirow[b]{2}{*}{ Reference } & \multicolumn{2}{|c|}{ Fine motor } & \multicolumn{2}{|c|}{ Gross motor } & \multirow{2}{*}{$\begin{array}{l}\% \text { SLI } \\
\text { children } \\
\text { impaired } \\
\text { MABC/ } \\
\text { TOMI }\end{array}$} \\
\hline & Impaired & Unimpaired & Impaired & Unimpaired & \\
\hline Preis et al. (1997) & $\begin{array}{l}\text { aim-time }(\mathrm{LH})^{*} \\
\operatorname{tap}(\mathrm{RH})^{*} \\
\text { tap }(\mathrm{LH})^{* *} \\
\text { pegs }(\mathrm{RH})^{*} \\
\text { pegs }(\mathrm{LH})^{*}\end{array}$ & $\begin{array}{l}\text { aim-time }(\mathrm{RH}) \\
\text { aim-errors }(\mathrm{RH}) \\
\text { aim-errors (LH) }\end{array}$ & - & - & - \\
\hline $\begin{array}{l}\text { Hill (1998) } \\
\text { Hill et al. (1998) }\end{array}$ & - & - & - & - & $57.9^{* * *}$ \\
\hline Rintala et al. (1998) & - & - & - & - & 71 \\
\hline
\end{tabular}

$\dagger$ None tested.

${ }^{*} p<0.05,{ }^{* *} p<0.01,{ }^{* * *} p<0.001$ (where no marking is given, $p$ is unknown).

Table 3. Performance of specific language impairment subgroups on fine motor tasks, showing direction of any significant differences between subgroups

Reference Task Subgroup comparison

Wiznitzer et al. (1986) peg moving

Bishop and Edmundson peg moving (1987)

Bradford and Dodd (1994)

Bradford and Dodd (1996)

Fein et al. (1996) motor accuracy

speed and dexterity

pegs (RH)

pegs (LH)

Seguin

Formboard verbal dyspraxia $=$ phonologic - syntactic $<$ lexical-syntactic $=$ semantic-pragmatic

4 years: SLI-good outcome $<$ control [ 4.5 onwards, SLI-good outcome $=$ control] 4 and 4.5 years: SLI-poor outcome $<$ control [5.5; SLI-poor outcome $=$ control] all ages: general delay $<$ control phonologically inconsistent errors $<$ phonologically consistent errors $=$ phonological delay phonologically inconsistent errors $=$ developmental verbal dyspraxia $<$ phonologically consistent errors $=$ phonological delay

$\mathrm{LAD}=\mathrm{NALIQ}<\mathrm{HAD}=\mathrm{DLD}$

$\mathrm{NALIQ}<\mathrm{LAD}<\mathrm{HAD}=\mathrm{DLD}$

NALIQ, LAD $<$ DLD

NALIQ, LAD $<$ HAD

$\mathrm{NALIQ}=\mathrm{LAD}<\mathrm{HAD}=\mathrm{DLD}$

DLD, developmental language disorder; HAD, high-functioning autistic disorder; LAD, lowfunctioning autistic disorder; NALIQ, non-autistic low-functioning disorder.

children with SLI tend to be unimpaired versus their normally developing peers (Johnston et al. 1981, Preis et al. 1997) with the exception of performance on the Ayres (1980) Motor Accuracy Test-Revised (Bradford and Dodd 1994). For gross motor function, typical difficulties lie (although not exclusively) in the area of balance (Johnston et al. 1981, Powell and Bishop 1992, Gross-Tsur et al. 1996). Table 2 provides details of the fine and gross motor tasks assessed and of the 
performance profile (including magnitude of the group differences) for the children with SLI in those 19 studies where a normally developing control group was used.

A further question concerns the performance profile of subgroups of children with SLI on tests of fine and gross motor function. Five of the studies identified provide subgroup data for fine motor tasks. Table 3 shows the tasks used and subgroup performance profiles for these studies. While few conclusions can be drawn from this table because studies have focused on different tasks and/or subgroups, clearly subgroups do differ in their performance on tasks. Children with semantic comprehension and formulation deficits showed superior performance on a peg moving task compared with children with expressive language deficits (Wiznitzer et al. 1986); children producing inconsistent phonological errors and those with developmental verbal dyspraxia were poorer at peg moving and motor accuracy tasks than those making phonologically consistent errors as well as those whose phonology was delayed (Bradford and Dodd 1994, 1996). Children with SLI improved on a peg-moving task between the age of 4 and 5.5 years, irrespective of the severity of their SLI (Bishop and Edmundson 1987). Finally, children with developmental language disorder performed significantly better than low-functioning children either with or without autistic disorders on tasks of peg moving, the Seguin Formboard (assessing visuo-spatial and motor skills) and on the Vineland Motor Domain which is concerned with the acquisition of functional motor skills in everyday life (Fein et al. 1996). Thus, although data are scant, it does appear that different subgroups of children with SLI may have different underlying deficits, a finding that warrants further, detailed investigation.

Cross-study comparison can also usefully be made between the fine/gross motor performance of children with SLI and children with DCD. Powell and Bishop (1992) used perceptual and motor tasks which had been found to discriminate children with DCD and normally developing controls with children with SLI. Children with SLI and matched controls undertook a battery of tests involving language ability, motor ability and visuo-spatial performance, including tasks used in the work of Charles Hulme $e t$ al. with children with DCD (e.g. Lord and Hulme 1987a). In comparison with age-matched controls, children with SLI performed more poorly on the visual discrimination and motor tasks, suggesting that the developmental clumsiness seen in these children with SLI was similar to that of children with DCD. However, there was not total similarity between the performance profile of the two groups of children. Children with SLI were unimpaired on tasks such as Block Design and Object Assembly (Wechsler 1992) which involve visuo-spatial processing, tasks which the child with DCD typically finds difficult (e.g. Lord and Hulme 1987b). Thus, although Powell and Bishop note that the presence of motor and perceptual deficits in SLI may arise from the same aetiology, they go on to say that they are not mediated by a common psychological mechanism.

A direct comparison of the performance of children with SLI and DCD within the same study and on an identical set of fine motor tasks is reported by Hill (1997), and can also be seen in studies using the Movement ABC or its predecessor the TOMI which are comprised purely of such tasks. A fundamental question addressed in the studies by Hill et al. was whether a similar pattern of coordination impairment is found in children with SLI and DCD. Hill (1997) found that children with SLI resembled not only those with DCD, but also younger, normally developing controls and that all three of these groups differed from age-matched normally developing controls on a finger opposition task. This was a sequential task and 
difficulties were found in both the number of sequences completed in 20 seconds and in the number of errors made. In contrast, none of the groups differed on a task of repetitive speeded finger tapping (in contrast to some of the studies shown in table 2).

In sum, it is clear that fine and gross motor deficits are characteristic of children with SLI.

\section{Praxis ability}

A second group of motor tasks used with children with SLI measure limb praxis ability. Praxis refers to our ability to produce purposeful skilled movements and involves the motor programming and motor integration required to execute complex and learned movements. Adult neurological patients experiencing difficulties in this domain are termed apraxic, while children are typically termed dyspraxic (see Dewey 1995 for a discussion of the use of this terminology). Before summarizing the results of studies of praxis ability in children with SLI, a brief description of the tasks involved will be given.

Tasks assessing limb praxis involve non-speeded gesture production and typically include the production of both representational (familiar) gestures and non-symbolic (unfamiliar) actions and action sequences. With reference to the studies reported here, representational gestures refer to gesture production of familiar actions/action sequences such as making a cup of tea or combing one's hair. The production of representational, or familiar, gestures is investigated in two response conditions; production of transitive gestures (which involve the use of an object such as a toothbrush) and the production of intransitive gestures (no object involved such as salute). Furthermore, gestures are required in two output conditions; pantomime to verbal command which in the case of transitive gestures are produced without the object (e.g. 'show me how you would brush your teeth using a toothbrush', 'show me how you would salute') and imitation of the experimenter pantomiming the same actions. In addition, non-symbolic (unfamiliar) single hand actions and sequences are produced, where the child copies the experimenter's hand posture/ sequence either with the experimenter's hand remaining as a model and/or with the experimenter's hand removed (direct imitation versus immediate recall).

Nine studies investigated some form of limb praxis ability in children with SLI. Table 4 provides details of the tasks used and of the performance profile (including magnitude of the group differences) for these tasks. Six studies investigated representational gestures (five of which focused on a quantitative analysis of gesture production). Only one of these six studies failed to find any impairment in the children with SLI in comparison with their normally developing controls (Aram and Horwitz 1983). However, it should be noted that some of the individual children in this study were impaired on this task. In all other studies quite substantial across-the-board quantitative limb praxis deficits were identified, with the exception of transitive gestures production in the Dewey and Wall (1997) study. In this latter study, however, very few gestures were included and, therefore, this difference may be explicable in terms of a less powerful dataset. Deficits were the case for both pantomime and imitation of transitive and intransitive gestures (Archer and Witelson 1988, Dewey et al. 1988, Dewey and Wall 1997, Hill 1998). In an analysis of the nature of the errors produced by the children reported in Hill (1998), Hill et al. 
Table 4. Studies shown in table 1 that have assessed limb praxis skill. Tasks used and the magnitude of any group differences are shown

\begin{tabular}{|c|c|c|c|c|c|c|}
\hline & \multicolumn{2}{|c|}{ Representational gestures } & \multicolumn{2}{|c|}{$\begin{array}{c}\text { Non-symbolic postures- } \\
\text { single }\end{array}$} & \multicolumn{2}{|c|}{$\begin{array}{c}\text { Non-symbolic postures- } \\
\text { sequences }\end{array}$} \\
\hline & Impaired & Unimpaired & Impaired & Unimpaired & Impaired & Unimpaired \\
\hline $\begin{array}{l}\text { Aram and } \\
\text { Horwitz (1983) }\end{array}$ & - & pantomime & - & - & - & - \\
\hline $\begin{array}{l}\text { Cermak et al. } \\
\text { (1986) }\end{array}$ & - & - & - & imitation & - & - \\
\hline $\begin{array}{l}\text { Archer and } \\
\text { Witelson (1988) }\end{array}$ & pantomime & - & time & accuracy & accuracy ${ }^{1}$ & box test ${ }^{2}$ \\
\hline $\begin{array}{l}\text { Dewey et al. } \\
\text { (1988) }\end{array}$ & $\begin{array}{l}\text { transitive- } \\
\text { single- } \\
\text { pantomime } \\
\text { transitive- } \\
\text { single- } \\
\text { imitation } \\
\text { intransitive- } \\
\text { single- } \\
\text { pantomime } \\
\text { intransitive- } \\
\text { single- } \\
\text { imitation } \\
\text { intransitive- }^{* *} \\
\text { sequence }^{* *}\end{array}$ & - & - & - & $\begin{array}{l}\text { command }^{*} \\
\text { imitation } \\
\text { action } \\
\text { pictures }^{* *}\end{array}$ & $\begin{array}{l}\text { learning of } \\
\text { individual } \\
\text { movements }\end{array}$ \\
\hline $\begin{array}{l}\text { Crary and } \\
\text { Anderson (1990) }\end{array}$ & - & - & - & - & imitation & - \\
\hline $\begin{array}{l}\text { Dewey and Wall } \\
\text { (1997) }\end{array}$ & intransitive & transitive & - & - & - & - \\
\hline Hill (1998) & $\begin{array}{l}\text { transitive- } \\
\text { pantomime } \\
\text { transitive } \\
\text { imitation } \\
\text { intransitive } \\
\text { pantomime } \\
\text { intransitive } \\
\text { imitation }^{* * 3}\end{array}$ & * & - & accuracy time & - & accuracy time \\
\hline Hill et al. (1998) & $\begin{array}{l}\text { errors: } \\
\text { pantomime } \\
\text { (transitive/in } \\
\text { imitation } \\
\text { (transitive/int }\end{array}$ & $\begin{array}{c}- \\
\text { transitive })^{* *} \\
\text { transitive }^{* * 3}\end{array}$ & - & - & - & - \\
\hline $\begin{array}{l}\text { Smith and Bryson } \\
\text { (1998) }\end{array}$ & - & - & - & accuracy & - & accuracy \\
\hline
\end{tabular}

- None tested.

${ }^{*} p<0.05,{ }^{* *} p<0.01,{ }^{* * *} p<0.001$ (where no marking is given, $p$ is unknown).

${ }^{1}$ Imitation of hand posture sequences.

2 Producing movements on a sequence box (such as that of Roy 1981).

${ }^{3}$ In all cases SLI are not significantly different from younger control group (and both are significantly different from age-matched control group). 
(1998) found that children with SLI produced the same types of errors (but to a greater extent) as did their normally developing peers.

In terms of the production of non-symbolic (unfamiliar) single hand postures, four studies assessed this, of which only one found any degree of impairment in children with SLI. In this case, Archer and Witelson (1988) found that children with developmental dysphasia were significantly slower than their normally developing peers in the accurate production of such postures. Other studies found no differences in time and accuracy of non-symbolic single gesture production (Cermak et al. 1986, Hill 1998, Smith and Bryson 1998). Finally, four studies assessed the production of non-symbolic hand sequences (two and/or three postures per sequence). Again, results are mixed with three studies finding that accuracy of reproduction of these sequences was impaired relative to normally developing controls (Archer and Witelson 1988, Dewey et al. 1988, Crary and Anderson 1990) and two studies finding that this was not a task that distinguished between the SLI and normally developing control groups (Hill et al. 1998, Smith and Bryson 1998). Certainly Dewey et al. found that learning of the individual movements in a sequence was unimpaired and it may be that it is the planning, integration and/or execution of a combination of postures into a sequence that causes such a deficit, where one exists.

Limited data are available for the performance of SLI subgroups on those praxis tasks where significant differences were found (table 5). Accuracy of representational gesture production was impaired relative to controls in Dewey et al.'s Sequenced Motion Rate-Impaired group, but not their Sequenced Motion Rate-Unimpaired group, as was performance in both of Hill's (1998) subgroups of SLI (Non-clumsySLI and Clumsy-SLI). In terms of the production of non-symbolic action sequences, Dewey et al.'s subgroups showed the same performance profile as for representational gesture production. Finally, children with developmental language disorders performed better than those on the autistic spectrum or those children who were low functioning but not considered to have autistic disorders when required to

Table 5. Performance of specific language impairment subgroups on limb praxis tasks, showing direction of any significant differences between subgroups

Task

Dewey et al. (1988)

pantomime representational gestures (transitive/intransitive)

non-symbolic sequences

Fein et al. (1996)

Hill (1998)

pantomime object use

pantomime transitive gestures

pantomime intransitive gestures

imitate transitive gestures

imitate intransitive gestures

Hill et al. (1998) representational gestures-error production (transitive/intransitive)
Subgroup comparison

SMR-impaired $<$ SMR-unimpaired SMR-impaired $<$ SMR-unimpaired $\mathrm{LAD}<\mathrm{NALIQ}<\mathrm{HAD}<\mathrm{DLD}$ clumsy-SLI $<$ non-clumsy-SLI clumsy-SLI $=$ non-clumsy-SLI clumsy-SLI $=$ non-clumsy-SLI clumsy-SLI $=$ non-clumsy-SLI clumsy-SLI = non-clumsy-SLI

SMR, Sequenced Motion Rate test; DLD, developmental language disorder; HAD, high-functioning autistic disorder; LAD, low-functioning autistic disorder; NALIQ, non-autistic low-functioning disorder. 
pantomime object use (Fein et al. 1996). Thus, the production of representational gestures appears to be impaired in children with SLI relative to normally developing controls, while results on the production of non-symbolic gestures is less clear.

Moving on to comparison of the limb praxis ability of children with SLI to those with DCD, a direct comparison of the performance of children with SLI and DCD within the same study and on an identical set of tasks is again reported by Hill et al.. Once again, Hill et al. found that children with SLI resembled not only those with DCD, but also younger, normally developing controls and that all three of these groups differed from age-matched normally developing controls on a range of limb praxis tasks. These tasks included a non-speeded task of representational gesture production (Hill 1998), as well as error production (Hill et al. 1998). In contrast the groups did not differ on the production of non-symbolic hand postures or sequences (Hill 1998). Thus, it is clear from these findings, as well as the studies presenting the performance of children with SLI on fine and gross motor tasks, that there is substantial co-morbidity between SLI and poor motor skill.

\section{Issues arising}

What are the implications of the studies reviewed here for current theories of SLI? Clearly the literature reveals that the difficulties of children with SLI fall outside the purely linguistic domain, thus casting doubt on explanations of the disorder in terms of grammar-specific, speech output or auditory perceptual deficits (see Bishop 1992 for a review). An explanation of SLI in terms of shared cognitive processes will, perhaps, provide a more plausible explanation of the observed co-occurrence of language and motor deficits in this disorder.

One group of tasks causing difficulties for children with SLI has a common element of speed being required. Difficulty in comparison with normally developing controls is seen, for example, on rapid auditory processing of non-verbal materials (e.g. Tallal and Piercy 1973), rapid picture naming and word recognition (Kail and Leonard 1986) and on more non-linguistic tasks including reaction time measures when mentally rotating unfamiliar shapes (Johnston and Ellis Weismer 1983) as well as the timed motor tasks shown in table 2. Such findings provide considerable evidence to suggest that children with SLI may process information more slowly than their normally developing peers, and that these findings are applicable across cognitive domains, rather than being associated solely with language function. Theories of SLI as a deficit in information-processing speed can, therefore, move away from explaining SLI in terms of a very specific impairment that exists at a discrete level, to a more general processing deficit. Two such accounts will be considered briefly. The first, Tallal's temporal processing theory of SLI and the second, Kail's Generalized Slowing hypothesis.

Tallal's well-known temporal processing theory of SLI (e.g. Tallal et al. 1993) explains the problems experienced by children with SLI as arising from a difficulty integrating sensory information that converges in rapid succession in the central nervous system. These difficulties were originally believed to occur as the result of a slow rate of processing of auditory information (e.g. Tallal and Piercy 1973), although as seen, more recent findings have suggested that the temporal processing difficulties of children with SLI reported by Tallal et al. are not unique to the auditory modality. This, then, is a pansensory deficit, affecting processing in multiple sensory modalities as well as motor output within the millisecond time frame. This 
inability to integrate sensory information that converges in rapid succession in the central nervous system has consequences primarily affecting the phonological system.

Kail's (1994) Generalized Slowing Hypothesis in children with SLI focuses directly on whether the postulated difficulties in processing speed in SLI are associated with some general versus specific aspect of cognitive processing. In Kail's theory it is assumed that in a normal child the time taken to complete a task is the sum of the absolute time taken to complete each component of the task (e.g. in a picture naming task, the time taken to recognize the picture, retrieve the picture's name, formulate and then produce the word). Through an analysis of five studies of reaction times in picture naming, Kail showed that the slowing factor in the performance of children with SLI reflected a general component of cognitive processing, rather than being specific to one component of the task. Thus, according to this account, children with SLI execute each component of a task more slowly, causing their performance to remain a proportion slower than that of their normally developing peers rather than to be slower than their peers by an absolute amount (e.g. 100 milliseconds). Thus, a deficit exists that affects the processing of all, rather than one component(s) of a task.

While processing speed may be an explanation of the motor deficits of children with SLI on the speeded tasks reviewed in table 1, additional deficits were seen on non-speeded tasks, as some of the fine motor tasks (Powell and Bishop 1992, Bradford and Dodd 1994, Owen and McKinlay 1997), gross motor (Powell and Bishop 1992) and certainly all the praxis tasks involved no timing constraints. Thus, while it may be that children with SLI have a generalized processing speed deficit, this can not account for all the deficits seen in SLI. What may account for these additional deficits on non-speeded tasks?

Remaining within the information-processing domain, information-processing capacity has been postulated as an alternative explanation for the observed linguistic deficits of children with SLI in comparison with their normally developing peers. In this account, difficulties on a task are experienced when its demands are high, suggesting that children with SLI lack the processing capacity to complete such tasks successfully. This type of account attributes the difficulties of children with SLI to limited processing capacity in a system that needs to integrate lexical, phonological and syntactic information on-line to produce and comprehend language in an age-appropriate fashion. Such an account has been used to explain impaired performance in a variety of linguistic-based tasks including grammatical processes (e.g. Rice et al. 1995), referential communication (Bishop and Adams 1992), constructive comprehension (Ellis Weismer 1985) and lexical learning tasks (Ellis Weismer and Hesketh 1993, 1996).

Moving away from purely linguistic tasks, Johnston and Smith (1989) showed that information-processing factors can be as important as language factors in explaining poor performance by children with SLI on a non-verbal judgement task, while Montgomery (1993) showed that information-processing capacity deficits could be identified in a non-linguistic haptic recognition task. Thus, providing evidence once more for an explanation of SLI in terms of a generalized cognitive processing deficit, rather than a linguistic-specific deficit.

While, to my knowledge, this hypothesis has not been applied specifically in the motor domain, it can certainly not be ruled out as an explanation: The more complex a task and/or the greater the number of processes requiring integration 
to complete a task, the more significant the level of impairment seen in children with SLI relative to their normally developing peers. For example, bead threading requires the coordination of fingers and thumb to pick up each individual bead, aligning each bead with the thread, pushing the thread through the bead and pulling each bead to the end of the thread, while maintaining a steady postural balance sitting on a chair and usually doing this as fast as possible (e.g. Powell and Bishop 1992). Throw-clap-catch, impaired in children with SLI (Powell and Bishop), requires all the components involved in throwing, clapping and catching - which individually are complicated enough-as well as the amalgamation of these. The praxis tasks are again complex, involving the selection of one or more motor programs as well as the integration of each individual motor program to make up a sequence and their execution. It is not difficult to imagine that a child with limited processing capacity could experience great difficulty with such tasks.

One caution should, however, be highlighted concerning the informationprocessing capacity deficit theory. Specifically, and as noted by Johnston (1991, 1994) and Bishop (1992), this theory, while attractive owing to its generality and subsequent applicability, suffers from this very point. While this informationprocessing theory of SLI marks a step towards integrating linguistic and nonlinguistic findings in children with SLI, until one can specify in greater detail the underlying processes of this account one must search for alternative, more testable explanations. It is to some other explanations that this paper now turns.

If information-processing theories of SLI are unable to explain at least some of the motor difficulties seen in children with SLI, what conclusions can be drawn concerning the nature of the co-occurrence of language and motor impairments on the basis of the research findings reviewed in this paper? Three of the possible explanations will be outlined. First, the language disorder plays a specific role in the deficits seen on the movement tasks. If this is the case, a high correlation between language impairment and motor performance would be expected, something which has not typically been reported (e.g. Preis et al. 1997, Hill 1998). While co-occurrence of deficits has been seen to be an indicator of correlation, and, therefore, association, this may be misleading as two deficits may arise from a common aetiology but may not be mediated by a common psychological mechanism. This will be touched on in more detail in a discussion of the third possible explanation, below.

A second explanation of the co-occurring deficits of language and movement relates to the question of whether the structure of the brain can shed light on the nature of the co-occurrence of language and motor deficits. Recent advances have allowed more sophisticated investigations of neuro-anatomy in children with neurodevelopmental disorders. With specific reference to imaging studies of SLI, there is no evidence of visually obvious lesions, although there is some evidence of atypical morphological asymmetries (e.g. Tallal and Katz 1989, Jernigan et al. 1991), including atypical perisylvian asymmetries (Plante et al. 1991, Jackson and Plante 1996). Atypical perisylvian asymmetries as well as cortical atrophy have also been reported in adults with familial language impairment (Kabani et al. 1998) as well as in firstdegree relatives of children with SLI versus controls (Plante 1991, Jackson and Plante 1996). Trauner et al. (2000) reported that the severity of brain abnormalities seen in a sample of 35 children with developmental language impairment correlated directly with the severity of a child's language deficit. Thus, although studies have shown some brain abnormalities in people with SLI, there is no evidence of damaged brain tissue, and, therefore, of brain damage as a cause of SLI. However, 
such findings do not rule out a neuro-anatomical explanation of symptom co-occurrence as the deficits may be the consequence of the anatomical contiguity of the neural substrates subserving language and motor functions. Certainly neurophysiological and neuropsychological evidence indicates links between language and movement processing at the neural level. Ojemann, for example, has shown that sequential movement and language share a common brain mechanism that appears to be located in the lateral perisylvian cortex of the dominant hemisphere (Ojemann 1984 for a review). Thus, it is not inconceivable that speech and at least some aspects of movement form a tightly coupled system. Abnormalities in both language and motor systems in SLI in turn provide evidence for this view. In addition, a recent account of the emergence of speech and gesture, drawing on the dynamic systems approach, supports this view that gesture and speech form a tightly coupled system (Iverson and Thelen 2000).

In the light of recent work, it would be valuable to consider the possible role of the cerebellum in causing co-occurring symptoms of language and movement deficits. Traditionally the cerebellum has been considered as solely a part of the motor control system. More recently, however, the cerebellum has been implicated not only in the learning of motor skills, but also in the learning of some cognitive and language skills (Leiner et al. 1991) as well as in selective attention (Akshoomoff and Courchesne 1992, Yamaguchi et al. 1998). Perhaps the cerebellum may be a link for these co-occurring deficits. It is certainly the case that in adults partial deficiency of the cerebellum leads to more generalized, rather than specific impairment that is not attributable to motor skills (Bracke-Tolkmitt et al. 1989). Diamond (2000) provides a comprehensive review and rationale for linking motor and other cognitive skill development with one another as well as with specific brain areas, most notably the neocerebellum and the dorsolateral prefrontal cortex. Future work is essential in this direction.

A third potential explanation for the apparent relationship between language and motor difficulties suggests that both deficits are indicators of underlying immaturity of brain development (i.e. compromised nervous systems). If this is the case, one would predict that children with other developmental disorders (e.g. dyslexia, ADHD) will have similar difficulties on these motor tests. This does, indeed, appear to be the case (e.g. Piek et al. 1999). Moreover, further supporting evidence for this view comes from longitudinal studies of children born prematurely. Such studies have shown that premature children have an increased likelihood of both language and motor delay and/or abnormalities later in development (Jongmans et al. 1993, Le Normand et al. 1995). Indeed in a longitudinal study, Le Normand et al. assessed children born prematurely at both 2 and 3 years 6 months of age, finding no correlation between language and motor performance at either age. These authors concluded that such a finding provides some evidence of the autonomy of language and motor development in preterm children. This again suggests that the motor system reflects systematic developmental changes that are a function of the maturational processes of the nervous system.

In his theory of neurolinguistic development, Locke $(1994,1997)$ has postulated the separateness of language and motor processes, suggesting that a maturational process regulates the development of each skill. According to this account, SLI starts out as a general neuromaturational delay that includes motor immaturity. Haynes and Naidoo (1991) report, for example, that only 44\% of a sample of 156 British children with severe developmental language delays were walking unaided at the age of 15 months and that $34 \%$ of them did not walk until 18 months or later. This is 
a percentage ten times higher than that expected in a typically developing population. Similar results have recently been reported by Trauner et al. (2000). As time passes, this delay evolves and other cognitive delays are seen, including the prominent linguistic symptoms that distinguish SLI. Locke argues that there is a critical period for activation of a species-typical linguistic mechanism. Locke (1994) gives the example of utterance acquisition, arguing that an utterance mechanism operates on stored utterances and requires internal lexical pressure to operate at a full level of efficiency. If little utterance material is stored, then the mechanism will not be activated appropriately. Locke argues that this mechanism has an optimal biological point and thus its viability decreases if sufficient words are not learnt, causing the mechanism to operate poorly. This account explains the delayed start to language acquisition as well as the lack of a complete 'catching-up' of linguistic functioning. Locke (1994) summarizes his account by arguing that delayed neurological development interacting with declining language-learning sensitivity causes language disorders. According to this account, a neuro-anatomical delay is responsible, in turn, for language, motor and other cognitive deficits (Locke 1997). Thus, each cognitive deficit is an index of a brain whose development is delayed. This account includes, therefore, a critical period concept, boosting for example, Bishop and Edmundson's (1987) maturational lag hypothesis of SLI. In their longitudinal study the language and peg moving skills of children with SLI developed at the same rate as their normally developing peers, but started later and failed to catch up.

In relation to the findings reviewed in table 1 and the resulting discussion, and specifically the studies including a younger normally developing control group, Locke's account gains support from the studies reported by Hill et al., where the motor performance of children with SLI resembled that of a younger normally developing motor matched control group, but the performance of both groups differed significantly from a normally developing control group matched for chronological age to those children with SLI. In addition, a similar performance profile was found by these researchers on tasks involving proprioception (Hill 1997) and behavioural aspects of handedness (Hill and Bishop 1998).

Thus, if neuromaturational development is slow, then delayed development of both language and motor skills will occur. In this way the motor system reflects systematic developmental changes that are a function of the maturational process of the nervous system (and other cognitive systems will do the same). With this view one would expect concomitant language, motor and other cognitive difficulties, as slow development would occur within various domains. Such theories suggest that a neuromaturational delay may be responsible for both language and motor deficits, but that neither deficit causes the other.

\section{Concluding remarks}

We are clearly a long way from understanding the true scope of neurodevelopmental disorders of language and movement. Having reviewed the literature, and despite the fact that this review was not exhaustive and can only be seen as indicative, it is clear that there is substantial co-morbidity between SLI and poor motor skill, and that the motor deficits seen in SLI are similar to those seen in other neurodevelopmental disorders such as DCD. This, in turn, suggests that these may be symptoms rather than specific disorders, and that concomitance of these symptoms is the rule rather than the exception. While it is possible that SLI could be a linguistic deficit with 
concomitant motor deficits, rather than having a single unifying cause for all cognitive and motor deficits, the weight of evidence points against this view with possible explanations in terms of a deficit in a general underlying process seeming more appealing. Accounts in terms of neuromaturational delay (e.g. Locke 1994, 1997) or of brain-behaviour relations (e.g. Diamond 2000) are particularly sympathetic to this view.

A further issue concerns subgroups of SLI. Could it be that children with SLI who experience motor difficulties are a subgroup of those with SLI? Given the studies reviewed in this paper, as well as the small number of studies focusing on SLI subgroups defined in terms of language abilities, this seems unlikely. A more likely scenario is that the majority of children with SLI experience certain, significant motor difficulties. The performance profile of the children with SLI by Hill et al. in particular supports this notion: children with SLI were split into two subgroups on the basis of their motor performance on the standardized test the Movement ABC. Those children with SLI who were identified as experiencing significant motor difficulties on this test (falling below the 15th percentile, a cut-off considered to identify significant impairment; clumsy-SLI) were compared with those falling above this cut-off and who were, therefore, considered to be developing in a motorically normal fashion (non-Clumsy SLI). Neither group differed from one another in their performance on experimental motor measures and both SLI subgroups differed in relation to age-matched normally developing controls (Hill 1998, Hill et al. 1998). While the datapool is small, such findings are suggestive of motor difficulties being the rule rather than the exception in SLI.

In the past, the majority of work on neurodevelopmental disorders has focused on documenting difficulties experienced by these children in the specific domain of their diagnosis. Clearly one needs to look further than this. While it is evident that there is symptom overlap in what are generally considered to be separate disorders, one is still a long way off from understanding how deficits in different domains are associated.

The only guaranteed conclusion that one can, currently, draw is that the deficits of children with SLI are not specific to language. While the evidence is scant and inconclusive, it is suggestive of overlapping rather than distinct disorders and one must, therefore, be aware of the risk that language delay has for additional motor impairments. Given the evidence reviewed it is plausible that while the underlying aetiology of these disorders is the same, the behavioural expressions of disorders are different due to various factors such as the timing and severity of disruption to brain development (e.g. Powell and Bishop 1992, Kaplan et al. 1998).

Accounts of the causes of SLI and motor deficits, as well as of their possible association will benefit from both detailed descriptions and comparisons of these disorders. Considering the prevalence of these difficulties, with estimates of forms of SLI at 5-7\% (Tomblin et al. 1997) and DCD at 6\% (APA 1994), and their increased incidence in other neurodevelopmental disorders, it is imperative that further understanding of the difficulties seen in these disorders must be obtained. Such substantial overlap in disorders suggests the possibility of a single underlying aetiology. Despite the difficulties associated with the investigation of neurodevelopmental disorders and skill development, the advancement of such an understanding must not be ignored.

\section{Acknowledgements}

The author acknowledges the invaluable discussions with Dorothy Bishop that led to the formulation of the ideas presented here, as well as for helpful comments from the anonymous reviewers. 


\section{References}

Aкshoomoff, N. A. and Courchesne, E., 1992, A new role for the cerebellum in cognitive operations. Behavioral Neuroscience, 106, 731-738.

American Psychiatric Association, 1994, Diagnostic and Statistical Manual of Mental Disorders (Washington, DC: APA).

Annett, M., 1972, The distribution of manual asymmetry. British Journal of Psychology, 63, 343-358.

Aram, D. M. and Horwitz, S. J., 1983, Sequential and non-speech praxic abilities in developmental verbal apraxia. Developmental Medicine and Child Neurology, 25, 197-206.

Archer, L. A. and Witelson, S. F., 1988, Manual motor functions in developmental dysphasia. Journal of Clinical and Experimental Neuropsychology, 10, 47.

Ayres, A. J., 1980, Southern California Sensory Integration Test (California: Western Psychological Services).

Bishop, D. V. M., 1992, The underlying nature of specific language impairment. Journal of Child Psychology and Psychiatry, 33, 3-66.

Bishop, D. V. M., 1997, Uncommon Understanding: Development and Disorders of Language Comprehension in Children (Hove: Psychology Press).

Bishop, D. V. M. and Adams, C., 1992, Comprehension problems in children with specific language impairment: literal and inferential meaning. Journal of Speech and Hearing Research, 35, 119-129.

Bishop, D. V. M. and Edmundson, A., 1987, Specific language impairment as a maturational lag: evidence from longitudinal data on language and motor development. Developmental Medicine and Child Neurology, 29, 442-459.

Bracke-Tolkmitt, R., Linden, A., Canavan, A. G. M., Rockstroh, B., Scholz, E., Wessel, K. and Diener, H. C., 1989, The cerebellum contributes to mental skills. Behavioural Neuroscience, 103, 442-446.

Bradford, A. and Dodd, B., 1994, The motor planning abilities of phonologically disordered children. European Journal of Disorders of Communication, 29, 349-369.

Bradford, A. and Dodd, B., 1996, Do all speech-disordered children have motor deficits? Clinical Linguistics and Phonetics, 10, 77-101.

Bruininks, R., 1978, Bruininks-Oseretsky Test of Motor Proficiency (Circle Pines: American Guidance Service).

Cermak, S. A., Ward, E. A. and Ward, L. M., 1986, The relationship between articulation disorders and motor coordination in children. American Journal of Occupational Therapy, 40, 546-550.

Crary, M. A. and Anderson, P., 1990, Speech and nonspeech motor performance in children with suspected dyspraxia of speech. Journal of Clinical and Experimental Neuropsychology, 12, 63.

Crary, M. A. and Towne, R. L., 1984, The asynergistic nature of developmental verbal dyspraxia. Australian Journal of Human Communication Disorders, 12, 27-37.

Dewey, D., 1995, What is developmental dyspraxia? Brain and Cognition, 29, 254-274.

Dewey, D., Roy, E. A., Square-Storer, P. A. and Hayden, D., 1988, Limb and oral praxic abilities of children with verbal sequencing deficits. Developmental Medicine and Child Neurology, 30, 743-751.

Dewey, D. and WALL, K., 1997, Praxis and memory deficits in language-impaired children. Developmental Neuropsychology, 13, 507-512.

Diamond, A., 2000, Close interrelation of motor development and cognitive development and of the cerebellum and prefrontal cortex. Child Development, 71, 44-56.

Doll, E. A., 1946, The Oseretsky Tests of Motor Proficiency: A Translation from the Portuguese Adaptation (Minneapolis: Education Test Bureau).

Dunn, H. G., Ho, H. H., Crichton, J. U., Robertson, A. M., McBurney, A. K., Grunau, R. V. E. and Penfold, S. P., 1986, Evolution of minimal brain dysfunctions to the age of 12-15 years. In H. G. Dunn (ed.), Sequelae of Low Birthweight: The Vancowver Study (London: Mac Keith), pp. 249-272.

Ellis Weismer, S., 1985, Constructive comprehension abilities exhibited by language-disordered children. Journal of Speech and Hearing Research, 28, 175-184.

Ellis Weismer, S. and Hesketh, L. J., 1993, The influence of prosodic and gestural cues on novel word acquisition by children with specific language impairment. Journal of Speech and Hearing Research, 39, 177-190.

Ellis Weismer, S. and Hesketh, L. J., 1996, Lexical learning by children with specific language impairment: effects of linguistic input presented at varying speaking rates. Journal of Speech and Hearing Research, 39, 177-190.

Fein, D., Dunn, M., Allen, D. A., Aram, D. M., Hall, N., Morris, R. and Wilson, B. C., 1996, 
Language and neuropsychological findings. In I. Rapin (ed.), Preschool Children with Inadequate Communication: Developmental Language Disorder, Autism, Low IQ (Cambridge: Cambridge University Press), pp. 123-154.

Griffiths, R., 1970, The Abilities of Young Children (High Wycombe: ARICD/Test Agency).

Gross-Tsur, V., Manor, O., Joseph, A. and Shalev, R. S., 1996, Comorbidity of developmental language disorders and cognitive dysfunction. Annals of Neurology, 40, 338-339.

Gubbay, S. S., 1975, The Clumsy Child: A Study of Developmental Apraxic and Agnosic Ataxia (London: W. B. Saunders).

Haynes, C. and Naidoo, S., 1991, Children with Specific Speech and Language Impairment (London: Mac Keith).

Henderson, S. E. and Sugden, D. A., 1992, Movement Assessment Battery for Children (Sidcup: Psychological Corp.).

HiLl, E. L., 1997, An investigation of the motor deficits in developmental coordination disorder and specific language impairment. $\mathrm{PhD}$ thesis, University of Cambridge.

HiLl, E. L., 1998, A dyspraxic deficit in specific language impairment and developmental coordination disorder? Evidence from hand and arm movements. Developmental Medicine and Child Neurology, 40, 388-395.

HiLl, E. L. and Bishop, D. V. M., 1998, A reaching test reveals weak hand preference in specific language impairment and developmental coordination disorder. Laterality, 3, 295-310.

HiLl, E. L., Bishop, D. V. M. and Nimmo-Smith, I., 1998, Representational gestures in developmental co-ordination disorder and specific language impairment: error-types and the reliability of ratings. Human Movement Science, 17, 655-678.

Hughes, M.-A. and Sussman, H. M., 1983, An assessment of cerebral dominance in languagedisordered children via a time-sharing paradigm. Brain and Language, 19, 48-64.

Iverson, J. M. and Thelen, E., 2000, Hand, mouth and brain: the dynamic emergence of speech and gesture. Journal of Consciousness Studies, 6, 19-40.

Jackson, T. and Plante, E., 1996, Gyral morphology in the posterior Sylvian region in families affected by developmental language disorder. Neuropsychology Review, 6, 81-94.

Jenkins, E. and Lohr, F. E., 1964, Severe articulation disorders and motor ability. Journal of Speech and Hearing Disorders, 29, 286-292.

Jernigan, T., Hesselink, J. R., Sowell, E. and Tallal, P., 1991, Cerebral structure on magnetic resonance imaging in language- and learning-impaired children. Archives of Neurology, 48, 539-545.

Johnston, J., 1988, Specific language disorders in the child. In N. Lass, L. McReynolds, J. Northern and D. Yoder (eds), Handbook of Speech-Language Pathology and Audiology (Toronto: Decker), pp. 685-715.

Johnston, J., 1991, Questions about cognition in children with language impairment. In J. Miller (ed.), Research on Child Language Disorders (Austin: Pro-Ed.), pp. 299-307.

Johnston, J., 1994, Cognitive abilities of children with language impairment. In R. Watkins and M. Rice (eds), Specific Language Impairments in Children (Baltimore: Paul H. Brookes), pp. 107-121.

Johnston, J. R. and Ellis Weismer, S., 1983, Mental rotation abilities in language-disordered children. Journal of Speech and Hearing Research, 26, 397-403.

Johnston, J. R. and Smith, L. B., 1989, Dimensional thinking in language impaired children. Journal of Speech and Hearing Research, 32, 33-38.

Johnston, R. B., Stark, R. E., Mellits, E. D. and Tallal, P., 1981, Neurological status of languageimpaired and normal children. Archives of Neurology, 10, 159-163.

Jongmans, M., Henderson, S., De Vries, L. and Dubowitz, L., 1993, Duration of periventricular densities in preterm infants and neurological outcome at 6 years of age. Archives of Disease in Childhood, 69, 9-13.

Kabani, N. J., Macdonald, D., Evans, A. and Gopnik, M., i998, Neuro-anatomical correlates of familial language impairment: A preliminary report. Journal of Neurolinguistics, 11, 203-214.

KAIL, R., 1994, A method for studying the generalized slowing hypothesis in children with specific language impairment. Journal of Speech and Hearing Research, 37, 418-421.

KaIL, R. and Leonard, L., 1986, Word-finding Abilities in Language-Impaired Cbildren, Monographs 25 (American Speech and Hearing Association).

Kaplan, B. J., Wilson, B. N., Dewey, D. and Crawford, S., 1998, DCD may not be a discrete disorder. Human Movement Science, 17, 471-490.

Katz, W., Curtiss, S. and Tallal, P., 1992, Rapid automatized naming and gesture by normal and language-impaired children. Brain and Language, 43, 623-641. 
Kilshaw, D. and Annett, M., 1983, Right- and left-hand skill. I: Effects of age, sex and hand preference showing superior skill in left-handers. British Journal of Psychology, 74, 253-268.

KIrK, S. A., McCarthy, J. J. and KIrK, W. D., 1968, Illinois Test of Psycholinguistic Abilities (Urbana: University of Illinois Press).

Le Normand, M. T., Vaivre-Douret, L. and Delfosse, M. J., 1995, Language and motor development in pre-term children: some questions. Child: Care, Health and Development, 21, 119-133.

Leiner, H. C., Leiner, A. L. and Dow, R. S., 1991, The human cerebro-cerebellar system: its computing, cognitive and language skills. Behavioural Brain Research, 44, 113-128.

Locke, J. L., 1994, The gradual emergence of developmental language disorders. Journal of Speech and Hearing Research, 37, 608-616.

Locke, J. L., 1997, A theory of neurolinguistic development. Brain and Language, 58, 265-326.

Lord, R. and Hulme, C., 1987a, Kinesthetic sensitivity of normal and clumsy children. Developmental Medicine and Child Neurology, 29, 720-725.

Lord, R. and Hulme, C., 1987b, Perceptual judgements of normal and clumsy children. Developmental Medicine and Child Neurology, 29, 250-257.

Merrill Palmer. 1975, Mental Measurements of Preschool Children. Scale of Mental Tests (Chicago: Stoeltin).

Montgomery, J. W., 1993, Haptic recognition of children with specific language impairment: effects of response modality. Journal of Speech and Hearing Research, 36, 98-104.

Nicolson, R. I. and FawcetT, A. J., 1994, Comparison of deficits in cognitive and motor skills among children with dyslexia. Annals of Dyslexia, 44, 147-164.

OJemann, G. A., 1984, Common cortical and thalamic mechanisms for language and motor functions. American Journal of Physiology, 246 [special issue: Regulatory Integrative and Comparative Physiology], R901-903.

Owen, S. E. and McKinlay, I. A., 1997, Motor difficulties in children with developmental disorders of speech and language. Child: Care, Health and Development, 23, 315-325.

Piek, J. P., Pitcher, T. M. and Hay, D. A., 1999, Motor coordination and kinaesthesis in boys with attention deficit-hyperactivity disorder. Developmental Medicine and Child Neurology, 41, 159-165.

Plante, E., 1991, MRI findings in the parents and siblings of specifically language-impaired boys. Brain and Language, 41, 67-80.

Plante, E., Swisher, L., Vance, R. and Rapcsak, S., 1991, MRI findings in boys with specific language impairment. Brain and Language, 41, 52-66.

Powell, R. P. and Bishop, D. V. M., 1992, Clumsiness and perceptual problems in children with specific language impairment. Developmental Medicine and Child Neurology, 34, 755-765.

Preis, S., Schittler, P. and Lenard, H.-G., 1997, Motor performance and handedness in children with developmental language disorder. Neuropediatrics, 28, 324-327.

Rapin, I. and Allen, D., 1987, Developmental dysphasia and autism in pre-school children: Characteristics and subtypes. In Proceedings of the First International Symposium on Specific Speech and Language Disorders in Children (London: Association for All Speech Impaired Children).

Rice, M., Wexler, K. and Cleave, P., 1995, Specific language impairment as a period of extended optional infinitive. Journal of Speech and Hearing Research, 38, 850-863.

Rintala, P., Pienimäki, K., Ahonen, T. and Cantell, M., 1998, Effects of a psychomotor training programme on motor skill development in children with developmental language disorders. Human Movement Science, 17, 721-737.

Robinson, R. J., 1991, Causes and associations of severe and persistent specific speech and language disorders in children. Developmental Medicine and Child Neurology, 33, 943-962.

Roy, E. A., 1981, Action sequencing and lateralized cerebral damage: evidence for asymmetries in control. In J. Long and A. Baddeley (eds), Attention and Performance IX (Hove: Lawrence Erlbaum Associates), pp. 487-500.

Schwartz, M. and Regan, V., 1996, Sequencing, timing and rate relationships between language and motor skill in children with receptive language delay. Developmental Neuropsychology, 12, 255-270.

SMITH, I. M. and Bryson, S. E., 1998, Gesture imitation in autism I: non-symbolic postures and sequences. Cognitive Neuropsychology, 15, 747-770.

Sommers, R. K., 1988, Prediction of fine motor skills of children having language and speech disorders. Perceptual and Motor Skills, 67, 63-72.

Sparrow, S. S., Balla, D. A. and Cicchetti, D. V., 1984, Vineland Adaptive Behavior Scales (Circle Pines: American Guidance Service).

Stark, R. E. and Tallal, P., 1981, Perceptual and motor deficits in language impaired children. In R. W. Keith (ed.), Central Auditory and Language Disorders in Children (San Diego: College-Hill Press), pp. 121-144. 
Stott, D. H., Moyes, E. A. and Henderson, S. E., 1984, The Henderson Revision of the Test of Motor Impairment (London: Psychological Corp.).

Stutsman, R., 1931, Mental Measurement of Pre-school Children: With a Guide for the Administration of the Merrill-Palmer Scale of Mental Tests (Yonkers: World Book).

TAllal, P. and Katz, W., 1989, Neuropsychological and neuro-anatomical studies of developmental language/reading disorders: recent advances. In C. v. Euler, I. Lundberg and G. Lennerstrand (eds), Brain and Reading (New York: Stockton), pp. 183-196.

Tallal, P., Dukette, D. and Curtiss, S., 1989, Behavioral/emotional profiles of preschool languageimpaired children. Development and Psychopathology, 1, 51-67.

Tallal, P., Miller, S. and Fitch, R. H., 1993, Neurobiological basis of speech: a case for the preeminence of temporal processing. In P. Tallal, A. M. Galaburda, R. R. Llinás and C. von Euler (eds), Temporal Information Processing in the Nervous System: Special Reference to Dyslexia and Dysphasia (New York: New York Academy of Sciences), pp. 27-47.

Tallal, P. and Piercy, M., 1973, Developmental aphasia: impaired rate of non-verbal processing as a function of sensory modality. Neuropsychologia, 11, 389-398.

Tiffin, J., 1968, Purdue Pegboard Examiner's Manual (Rosemont: London House).

Tirosh, E. and Cohen, A., 1998, Language deficit with attention-deficit disorder: a prevalent co-morbidity. Journal of Child Neurology, 13, 493-497.

Tomblin, J. B., Records, N. L., Buckwalter, P., Zhang, X., Smith, E. and O'Brien, M., 1997, Prevalence of specific language impairment in kindergarten children. Journal of Speech and Hearing Research, 40, 1245-1260.

Trauner, D., Wulfeck, B., Tallal, P. and Hesselink, J., 2000, Neurological and MRI profiles of children with developmental language impairment. Developmental Medicine and Child Neurology, 42, 470-475.

WeChsler, D., 1992, Wechsler Intelligence Scale for Children (London: Psychological Corp.).

Wiznitzer, M., Rapin, I. and Allen, D., 1986, Motor function in school-age children with developmental language disorders. Annals of Neurology, 20, 413-414.

World Health Organisation, 1992, The ICD-10 Classification for Mental and Behavioural Disorders: Clinical Descriptions and Diagnostic Guidelines (Geneva: WHO).

Yamaguchi, S., Tsuchiya, H. and Kobayashi, S., 1998, Visuo-spatial attention shift and motor responses in cerebellar disorders. Journal of Cognitive Neuroscience, 10, 95-107. 